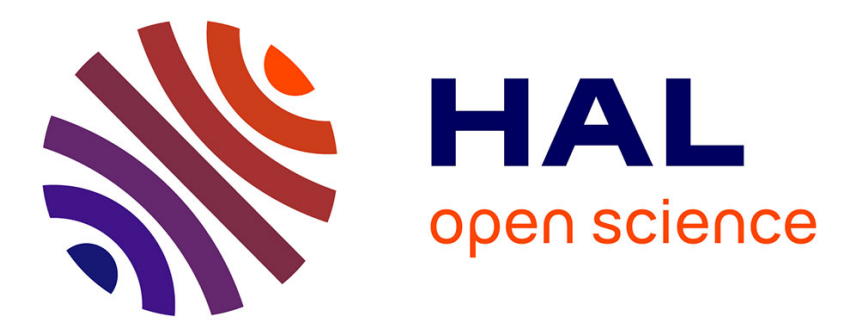

\title{
Detectability of junctions of underground electrical cables with a ground penetrating radar: Electromagnetic simulation and experimental measurements
}

Xiang Liu, Mohammed Serhir, Marc Lambert

\section{- To cite this version:}

Xiang Liu, Mohammed Serhir, Marc Lambert. Detectability of junctions of underground electrical cables with a ground penetrating radar: Electromagnetic simulation and experimental measurements. Construction and Building Materials, 2018, 158, pp.1099-1110. 10.1016/j.conbuildmat.2017.10.038 . hal-01631492

HAL Id: hal-01631492

https://hal-centralesupelec.archives-ouvertes.fr/hal-01631492

Submitted on 9 Nov 2017

HAL is a multi-disciplinary open access archive for the deposit and dissemination of scientific research documents, whether they are published or not. The documents may come from teaching and research institutions in France or abroad, or from public or private research centers.
L'archive ouverte pluridisciplinaire $\mathbf{H A L}$, est destinée au dépôt et à la diffusion de documents scientifiques de niveau recherche, publiés ou non, émanant des établissements d'enseignement et de recherche français ou étrangers, des laboratoires publics ou privés. 


\title{
Detectability of junctions of underground electrical cables with a ground penetrating radar: electromagnetic simulation and experimental measurements
}

\author{
Xiang Liu, Mohammed Serhir*, Marc Lambert* \\ GeePs / Group of electrical engineering - Paris, UMR CNRS 8507, CentraleSupélec, Univ. Paris-Sud, Université Paris-Saclay, \\ Sorbonne Universités, UPMC Univ Paris 06 \\ 3 \&6 11 rue Joliot-Curie, Plateau de Moulon 91192 Gif-sur-Yvette CEDEX, France
}

\begin{abstract}
For electricity distribution companies, being able to accurately detect the position of buried power cables using nondestructive methods is a crucial issue. The most important issue is the localization of the junction part linking the cables to each other where most maintenance operations are carried out. In this work we have conducted a feasibility study to confirm the relevance of high frequency Ground Penetrating Radar (GPR) to detect these buried junctions in their environment despite the clutter. The cables are buried in an inhomogeneous Earth medium at about one meter deep. Consequently, we have optimized a folded bowtie antenna to fit the frequency band $[0.5 \mathrm{GHz}-3 \mathrm{GHz}]$. Then a rigorous model of the cable is considered in the numerical study using the optimized antenna in a bi-static configuration. A full wave electromagnetic simulation software (CST MWS) has been used to study the detectability of the junction within dry and wet homogeneous sands then a classical Kirchhoff migration technique has been used to process the data and localize the junction. Finally, our analysis has been validated by measurements at a test site (real environment) to show the efficiency of the proposed analysis. The measured data are also post-processed using a digital filtering technique for clutter reduction and visibility enhancement of the buried cable.
\end{abstract}

Keywords: Ground penetrating radar; Ultra Wide band antenna; Full-wave electromagnetic simulation; migration

\section{Introduction}

Ground penetrating radar (GPR) is a well-known non-invasive system used for identification and localization

*Corresponding author: mohammed.serhir@centralesupelec.fr 


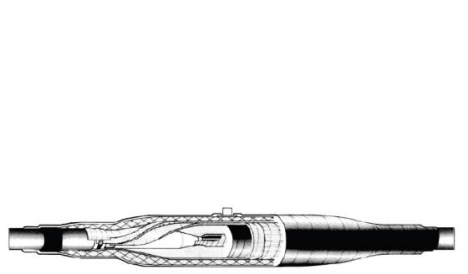

(a)

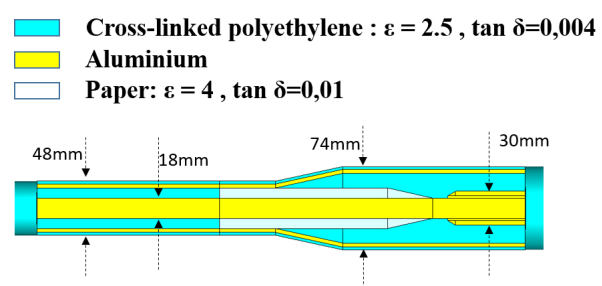

(b)

Figure 1: (a) A photography of the junction of underground electrical cables, (b) The junction detailed description for the electromagnetic modeling purpose, the junction length is $40 \mathrm{~cm}$

as the part of the power cable with a diameter outgrowth of $50 \%$ compared with the one of the cable. Such a diameter variation modifies the scattered field enough to distinguish the junction from the cable. The power cables are usually buried at $1 \mathrm{~m}$ depth in sandy environments $\left(\varepsilon_{r} \sim 4\right)$ and an example of real buried junction is presented in Figure 1 were geometric details are provided. This is one of the smallest junction used by Electricité De France Company (EDF). This work, aims at showing that a wide band GPR system covering the frequency band [0.5 GHz $-3 \mathrm{GHz}$ ] can allow us to reach the needed resolution $(3 \mathrm{~cm})$ to distinguish the contrast between the scattered fields due to the cable and the junction.

Thanks to the help of a full wave software (CST MWS) and its Finite Integration Technique a folded bowtie antenna operating at the frequency band $[0.5 \mathrm{GHz}, 3 \mathrm{GHz}]$ has been optimized and various scenarios have been studied either in terms of embedding Earth medium (dry/wet sand) or in terms of polarization (parallel/perpendicular). The geometric and electric description of the power cable embedded in a homogeneous dry or wet sandbox respectively are considered in the numerical model and the optimized antenna is used as transmitting and receiving structures. In fact, the authors of [19 26] have underlined the importance of the incident field modeling on the GPR imaging results. The corresponding received signal $\left(S_{21}\right)$ in a bi-static configuration along the buried scanned cable is then collected and treated using various filters in order to remove the clutter. Finally, the measurements are realized inside a controlled area of "EDF - R\&D" company with the laboratory of electrical material at Moret sur Loing site where multiple cables are buried and where the presented GPR study has been validated. The paper is organized as follows: section 2 is dedicated to describing the designed antenna. Section 3 proposes the full-wave simulation results for the junction detectability. Section 4 focuses on the on-site measurement results conducted at Moret sur Loing. Finally, a conclusion is drawn to outline the interest of the conducted study for utilities detection and localization in section 5 .

\section{The GPR antenna structure}

Ultra wideband antennas are widely used for GPR applications [27, 28]. These antennas can be TEM horn [29], biconical antenna [30, the bowtie, the lumped element loaded antennas [31. Here an optimized fractal folded bow-tie antenna for on-ground GPR has been chosen. This antenna is used in the vicinity of the soil (proximal antenna). Such an antenna belongs to the dipole antennas family, which is efficient and easy to design since the input port impedance depends on the flare angle of the bowtie. We have optimized the antenna with its symmetric excitation (BALUN) for the frequency band $[0.5 \mathrm{GHz}-3 \mathrm{GHz}]$. The geometrical description of the antenna is given in Figure 2 where the BALUN is also described. The antenna has been optimized in free space using the transient 


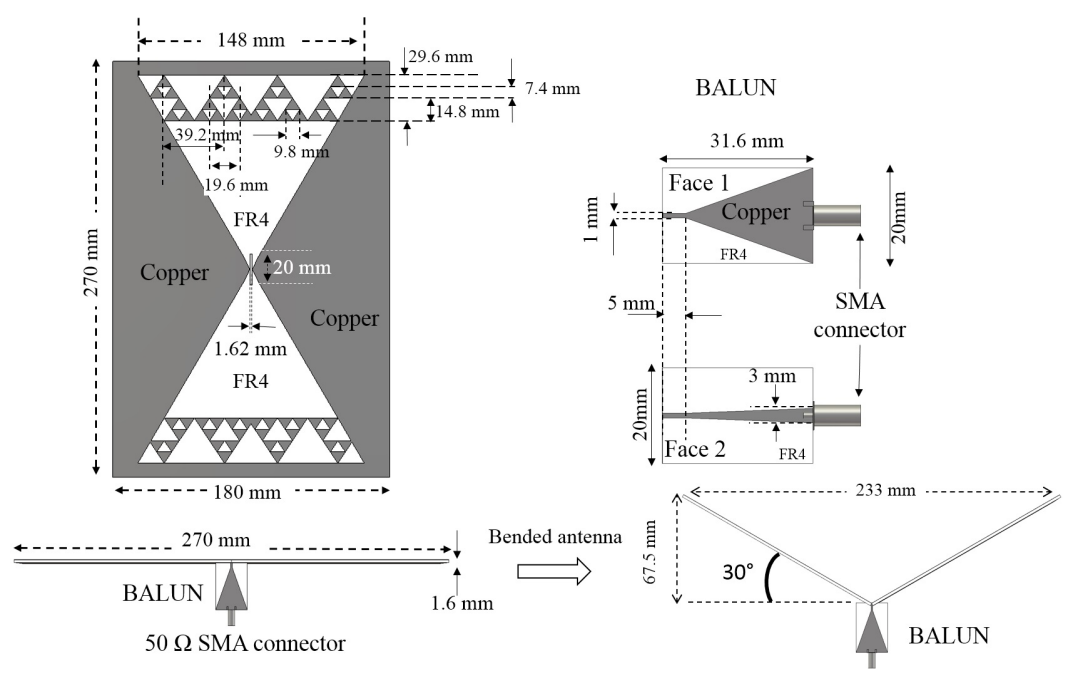

(a)
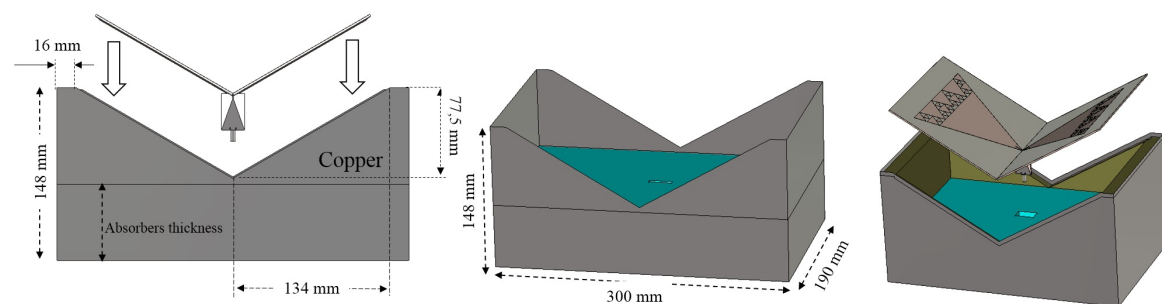

(b)

Figure 2: (a) V-Folded Bowtie Antenna (VFBA) description, (b) the cavity backed VFBA description.

solver provided by CST MWS and the measured reflection coefficient $\left(S_{11}\right)$ of the realized antenna is presented in Figure 3. In order to prevent the back-radiation of the antenna we need to transform it to unidirectional one. We can use a cavity as specified in many papers among which [32, 33] where a large cavity in comparison with the bowtie antenna size has been used. However, such a solution is not adapted to the GPR application since the size of the cavity has to be comparable with the size of the antenna as presented in [34. Nevertheless, the use of the cavity is inevitable because of the electromagnetic energy radiated from the back of the bow-tie antenna. Without a shielding around the antenna, the interferences with the external parasitic electromagnetic perturbations reduce significantly the signal to noise ratio of the measured data. In fact, the metallic cavity brings the protection to the GPR antennas and without a specific precaution, the coupling between the antenna and the shielding cavity will inevitably deteriorate the antenna matching.

In this paper we propose, besides using the cavity filled with absorbers, to bend the fractal bowtie antenna (as shown in Figure 2 to enhance the directivity of the antenna in the frequency band of interest [0.5 GHz $-3 \mathrm{GHz}]$. The idea of bending the antenna is inspired from TEM antennas as depicted in [35].

The $30^{\circ}$ bended antenna is labeled V-Folded Bowtie Antenna (VFBA). As shown in Figure 3 , the VFBA $S_{11}$ 6 is presented and compared with the $S_{11}$ of the VFBA with the shielding cavity filled with absorbers. The cavity backed VFBA presents $S_{11}<-10 \mathrm{~dB}$ for the frequency band $[0.75 \mathrm{GHz}-3 \mathrm{GHz}]$ and the cavity filled with absorbers $s$ did not disturb significantly the VFBA reflection coefficient $\left(S_{11}\right)$ over the frequency band $[0.75 \mathrm{GHz}-3 \mathrm{GHz}]$. 


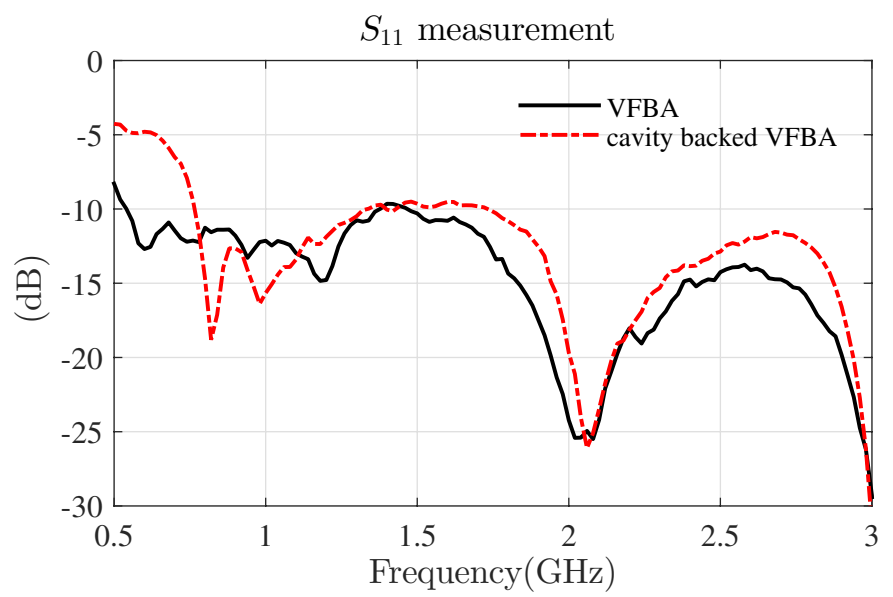

Figure 3: The measured reflection coefficients $\left(S_{11}\right)$ of the cavity backed VFBA and the VFBA.

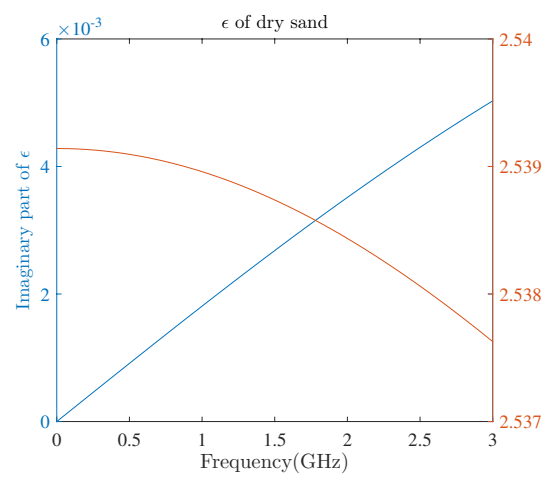

(a)

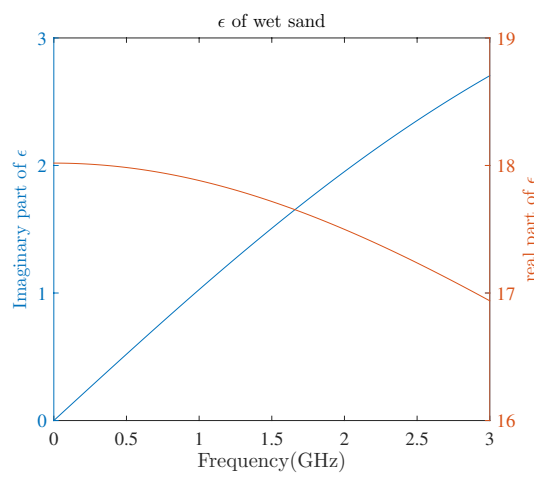

(b)

Figure 4: Permittivity of the sand used for the electromagnetic simulation, (a) dry sand, (b) wet sand.

\section{The electromagnetic modelling of the GPR scene}

From now, the optimized VFBA will be used as transmitter and receiver to illuminate the scene and collect the scattered field due to a buried cable in dry or wet sands. The permittivity of wet sand is defined for $20 \%$ humidity. The permittivity values used for our simulation are predefined in the CST MWS library and their real and imaginary part are given in Figure 4 whereas the GPR scene modeled in our study is described in Figure 5. Keeping the simulation time reasonably short (about 4 hours per antennas position) the cavity filled with absorbers for the antennas as shown in Figure 5 has not been considered. For the simulation of the GPR scene, we have used the transient solver of CST MWS with hexahedral meshing based on the spatial criterion $d x=d y=d z=\lambda / 12$ where $\lambda$ is calculated for the frequency $1.5 \mathrm{GHz}$. The total number of used mesh cells is 29 million for two VFBA placed in front of a sand volume of $1100 \mathrm{~mm}$ depth, $660 \mathrm{~mm}$ width and $1670 \mathrm{~mm}$ length.

The simulation is running on PC with 32 GByte RAM, over Intel Xeon CPU E5-1650 V3 3.5GHz. The excitation pulse is sent to the antenna via the coaxial connector of the BALUN and the simulation is stopped after 50 ns. For each position along the cable, this simulation takes $3 \mathrm{~h} 45 \mathrm{~min}$. In order to work with reduced size sandbox volume perfect matched layers (PML) have been used to prevent the echoes produced by the borders of the sand volume. For the case of dry sand scene, PML are placed around the sand volume to simulate an infinite sandy environment. For the case of a wet sand, the PML predefined in the CST software cannot deal with a dispersive environment and 


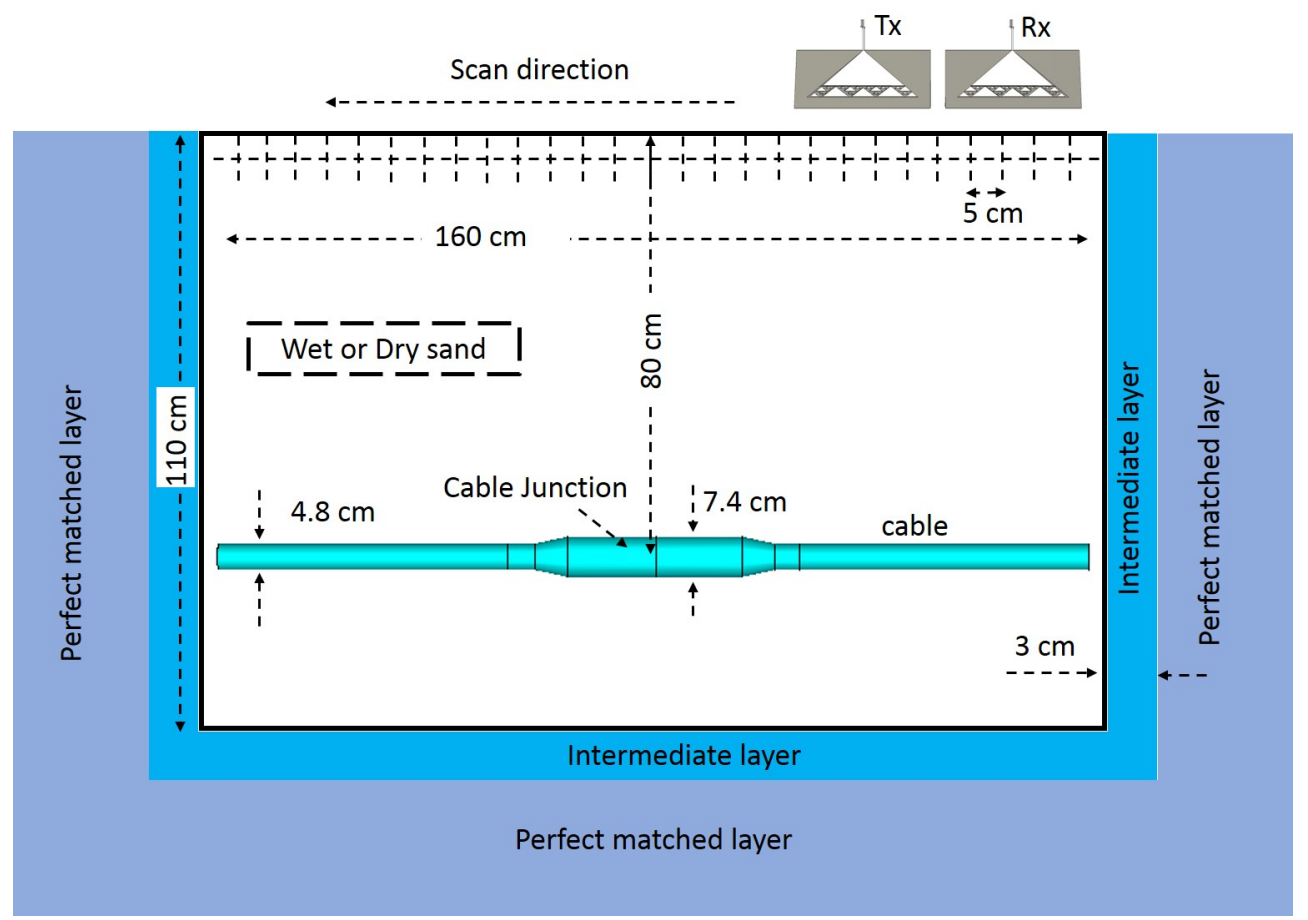

(a)

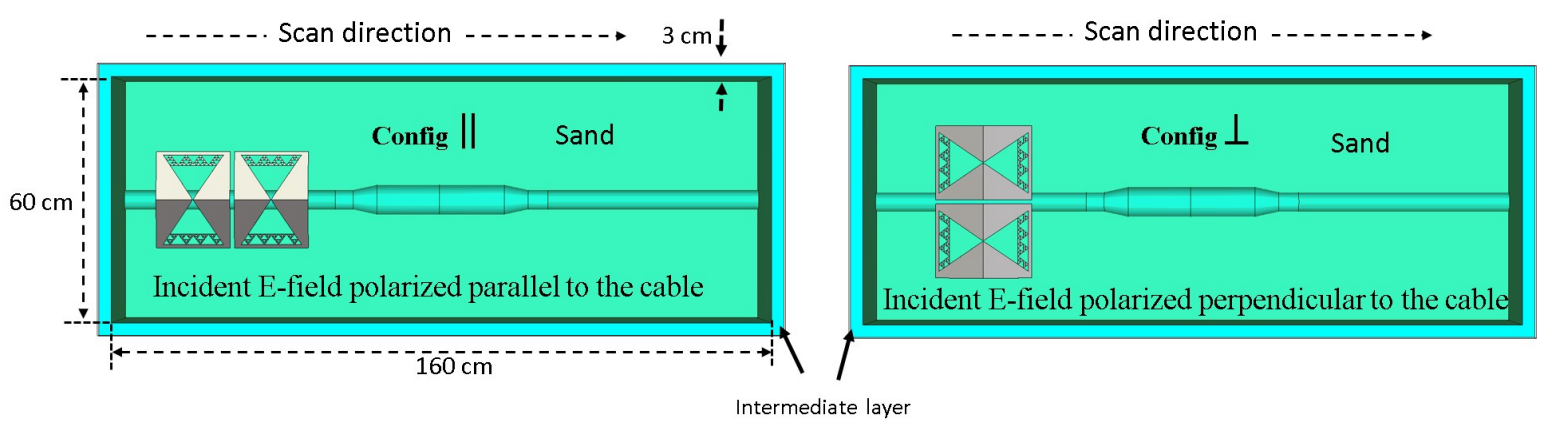

(b)

Figure 5: (a) The simulation configuration with the buried cable, the sandy environment and the transmitting and receiving antennas, (b) description of the up-view of the simulation configuration associated with the polarization of the transmitting and receiving antennas 

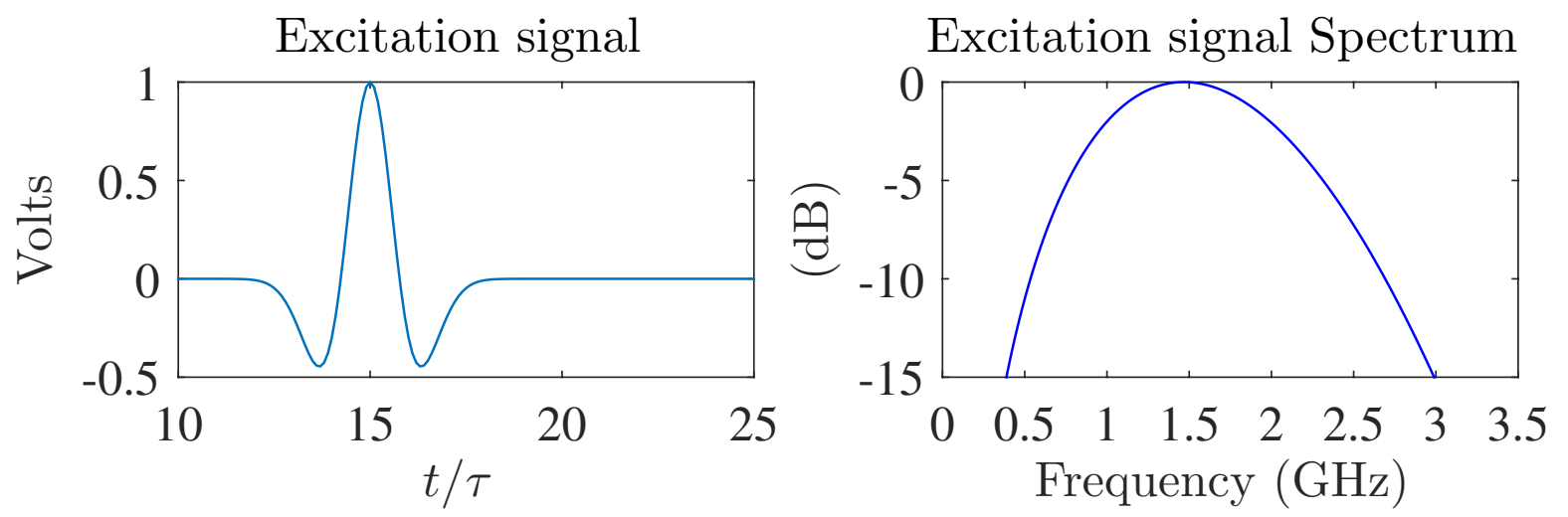

Figure 6: The used excitation signal and its frequency spectrum.

this is why an intermediate layer (IL) with a permittivity equal to the frequency-averaged value of the amplitude of the wet sand permittivity has been added. Adding the PML over the IL greatly helps in echoes attenuation. The PML play their role correctly since these have been defined for the IL containing non-dispersive material (Figure 5). We have optimized the thickness of the IL using CST MWS in order to reduce the echoes produced by the sand volume limitations. The IL thickness optimization is not the main subject of the present study and will not be detailed in the following however in our case a value of $3 \mathrm{~cm}$ has allowed a sufficient reduction (cancellation is not reached) of the echoes produced by the sandbox borders. Another solution would have been to use a larger sandy volume and filter out the echoes but with an important increase of the CPU time (more than 12 hours calculation per antenna position for the double of the sand volume) with respect to the proposed solution.

The efficiency of the proposed solution for the echoes cancellation due to the sandbox boundaries is demonstrated by comparing the results of background modeling (the field without the buried cable) in three configurations. In configuration C-1 a wet sand volume placed in free space without perfect matched layers nor intermediate layers is considered, then configuration C-2 is defined as a wet sand with PML around the sand volume then configuration C-3, where a wet sand volume with the PML and IL as presented in Figure 5 is used. The electromagnetic simulations are carried out in the time domain and the transmitting antenna is excited using the second derivative of the Gaussian signal. The excitation signal is expressed as

$$
e(t)=-\left[4 \alpha^{2}\left(\frac{t-t_{0}}{\tau}\right)^{2}-2 \alpha\right] \exp \left[-\alpha\left(\frac{t-t_{0}}{\tau}\right)^{2}\right]
$$

and its spectrum normalized at $f_{0}=1.5 \mathrm{GHz}$ are presented in Figure 6 for $\tau=2 \times 10^{-10} \mathrm{~s}, \alpha=0.85 / \tau^{2}$ and $t_{0}=15 \tau$ which covers the antenna frequency band $[0.5 \mathrm{GHz}-3 \mathrm{GHz}]$.

For each antennas measurement position (A-scan), the receiving antenna collects the field scattered by the sand volume and the transmission coefficient $S_{21}$ is exploited to construct the radargram presented in Figure $7 \mathrm{a}$. The center of the sandbox is considered as the origin of the axis and the scanning is carried from $[-0.5 \mathrm{~m}, 0.5 \mathrm{~m}]$ with a displacement step of $5 \mathrm{~cm}$.

As shown in Figure 7b the combination of the PML and the IL (C-3) reduces significantly the echoes resulting from the limitation of the sand volume whereas in configurations C-1 and C-2 those echoes are still visible (mainly the echoes related to the bottom of the sand box around a depth of $1.2 \mathrm{~m}$ ). For the three configurations, the crosstalk between the transmitting and receiving antennas is seen in Figure $7 \mathrm{~b}$ where the A-scan corresponding to the 

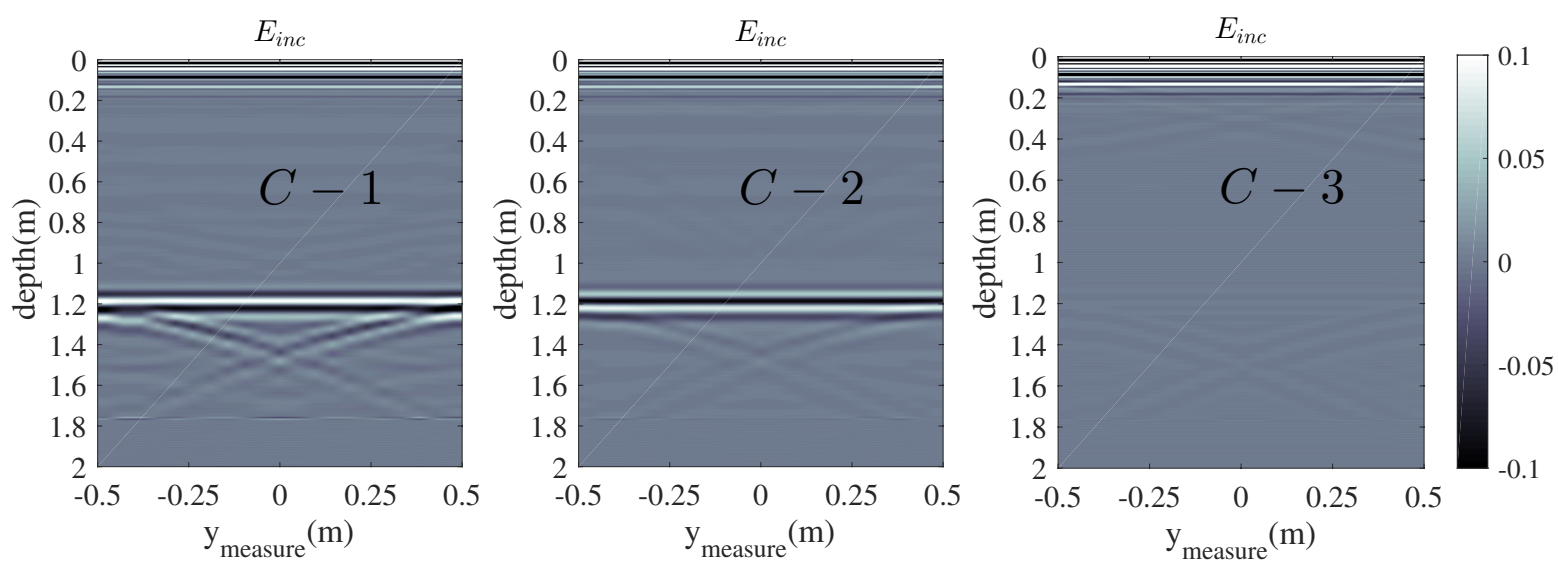

(a)

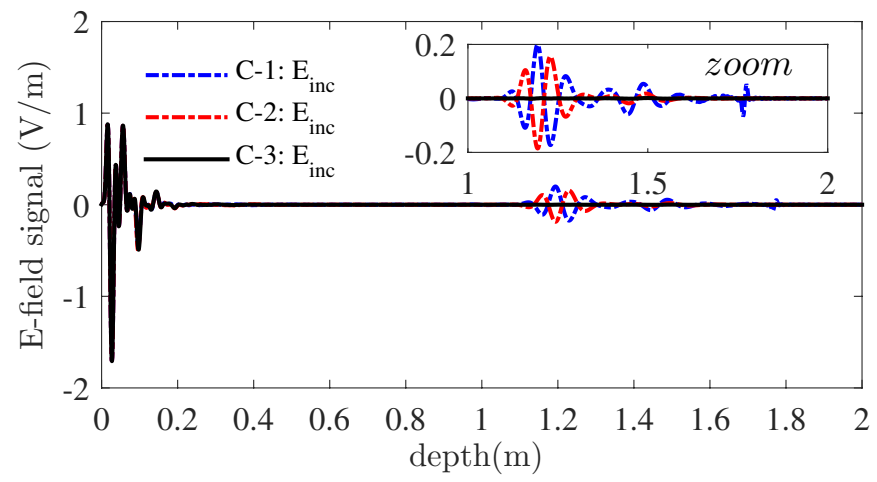

(b)

Figure 7: (a) The background modeling $\left(E_{\text {inc }}\right)$ for C-1, C-2, C-3 configurations (b) the A-scan of the central position $y_{\text {meas }}=0$ for C-1, C-2 and C-3 configurations. 

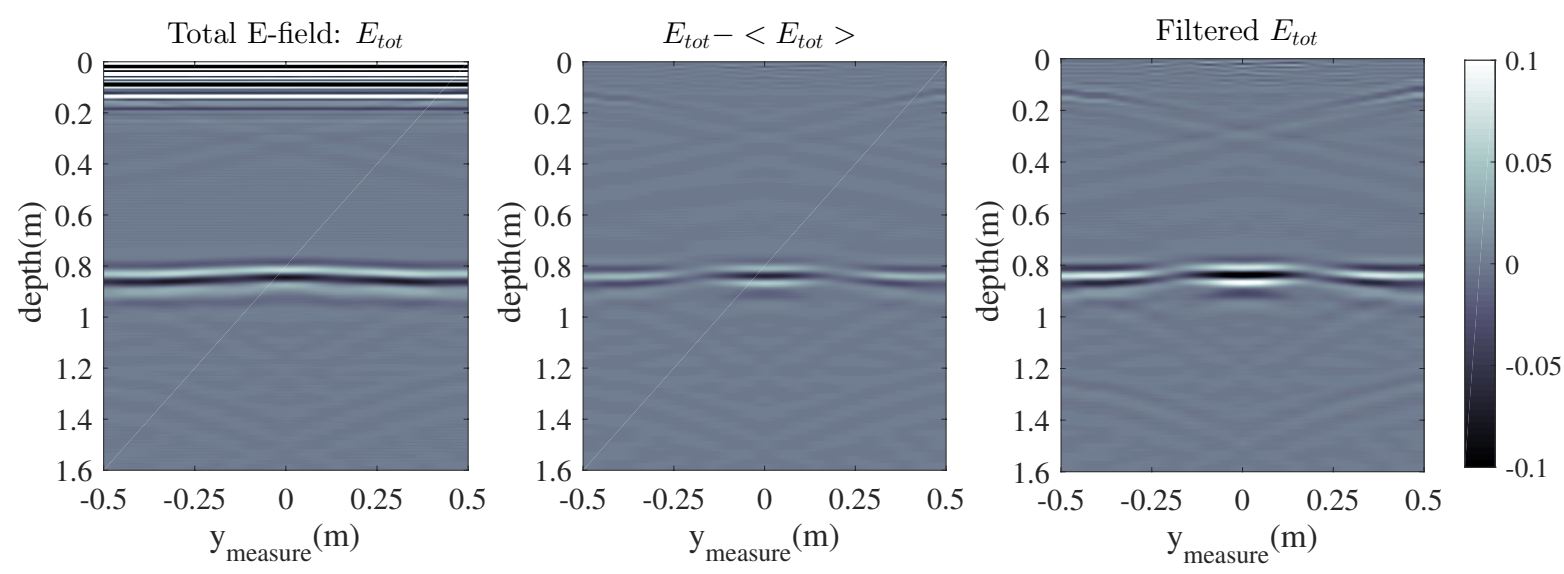

Figure 8: B-scan radargrams for $E_{\text {tot }}, E_{\text {tot }}-\left\langle E_{\text {tot }}\right\rangle$, filtered $E_{\text {tot }}$, for parallel configuration with wet sand.

central position $y_{\text {meas }}=0 \mathrm{~m}$ for $\mathrm{C}-1, \mathrm{C}-2$ and $\mathrm{C}-3$ are compared, as seen in the zooming part the C-3 configuration is efficient for the echoes attenuation. In the following, only the combination of the PML and IL will be considered.

Now a numerical study of the influence of the transmitting and receiving antennas polarization on the buried cable detection is performed. In Figure 5b an upper-view of the antennas disposition above the sandbox is depicted. In the first situation, the transmitting and receiving antennas are placed in order to align the polarization of the incident field with the buried cable and consequently the impinging E-field polarization is parallel to the scan direction along the cable (parallel configuration). In the second situation, the antennas are positioned so that the incident E-field is polarized perpendicularly to the scan direction (perpendicular configuration).

Using CST MWS to model the scene presented in Figure 5 for a wet sand leads to the B-scan radargrams presented in Figure 8 for the so-called parallel configuration. The total field $\left(E_{\text {tot }}\right)$ represents the measured field over the sandbox in the presence of the buried cable. From the $E_{\text {tot }}$ B-scan radargram, two clear echoes zones are identified, the first one is due to the antennas cross-talk combined with the air-soil interface whereas the second one is linked to the buried cable position. In order to get access to the scattered field, background removal techniques are needed to isolate the signature of the buried cable. Among them, two have been used in the following. The first one is one of the procedures described in [1] for clutter reduction by the GPR community, where the radargrams resulting from $E_{\text {tot }}-\left\langle E_{\text {tot }}\right\rangle$ where $\left\langle E_{\text {tot }}\right\rangle$ means averaged value of the B-scan radargram of $E_{\text {tot }}$ is used. The second one is the digital filtering technique proposed in [36], which is based on the design of a digital filter adapted to the B-scan. The high-pass filter to design aims at eliminating the clutter component in the spectral domain. The filtered radargrams are presented in Figure 8. These two clutter reduction techniques have shown comparable radargrams.

Four situations corresponding to dry and wet sand for parallel and perpendicular polarizations are studied and the corresponding radargrams are presented either for $E_{\mathrm{tot}}-\left\langle E_{\mathrm{tot}}\right\rangle$ and for filtered $E_{\mathrm{tot}}$ in Figure9. In all of them three areas can be identified in the signature of the buried cable. The first and the last areas corresponding to the scanning positions $0.25 \mathrm{~m}<y_{\text {meas }}<0.5 \mathrm{~m}$ and $-0.5 \mathrm{~m}<y_{\text {meas }}<-0.25 \mathrm{~m}$ characterize the echoes due to the cable. The in-between second area shows the echoes due to the central part of the cable (junction) located at $\left|y_{\text {meas }}\right| \leq 0.2 \mathrm{~m}$ . The sloping parts of the cable junction (Figure 5) produce the echoes situated between $\left(0.2 \mathrm{~m}<y_{\text {meas }}<0.25 \mathrm{~m}\right.$ and $-0.25 \mathrm{~m}<y_{\text {meas }}<-0.2 \mathrm{~m}$ ). The magnitude of the echoes gives qualitative information about the position of the junction. In Figure 9 the cable junction is located at $\left|y_{\text {meas }}\right| \leq 0.2 \mathrm{~m}$ corresponding to the maximum magnitude 
of $E_{\text {tot }}-\left\langle E_{\text {tot }}\right\rangle$ and of the filtered $E_{\text {tot }}$.

As it is seen in Figure 9, the amplitude of the echoes resulting from dry sand are higher than for wet sand due to the higher propagation losses of the latter. As expected, the parallel antenna polarization produces higher level echoes compared with the perpendicular one. Based on these four studied situations, a common conclusion arises; the outgrowth of the cable diameter (junction position) is characterized by stronger echoes which are localized at $\left|y_{\text {meas }}\right| \leq 0.2 \mathrm{~m}$ placed at $80 \mathrm{~cm}$ depth. When the antenna polarization is parallel to the cable, the impinging E-field is better coupled to the buried target, which increases the scattered echoes amplitude. On the contrary, in the perpendicular polarization, the coupling between the impinging E-field and the buried cable is lower, leading to a lower signature of the cable and its junction. As a conclusion and as expected in wet sand media, the radargram resolution is better and the parallel polarization is more efficient for the junction localization due to the strongest echoes amplitude.

In order to have a better understanding of the behavior of the B-scan radargram at the intermediate area between the junction and the cable around $y_{\text {meas }}= \pm 0.25 \mathrm{~m}$ the A-scan signals of $E_{\text {tot }}$ at the positions $y_{\text {meas }}=0 \mathrm{~m}($ junction$)$, $y_{\text {meas }}=0.25 \mathrm{~m}$ (transition part) and $y_{\text {meas }}=0.4 \mathrm{~m}$ (cable) are compared in Figure 10 . Comparing the E-field for the two polarizations at the junction central position $\left(y_{\text {meas }}=0 \mathrm{~m}\right)$ shows that the signal of parallel polarization results in a stronger signature. The outgrowth of the cable diameter at the junction position $\left(y_{\text {meas }}=0 \mathrm{~m}\right)$ justifies the differences between the E-field signals at the positions $y_{\text {meas }}=0 \mathrm{~m}$ and $y_{\text {meas }}=0.4 \mathrm{~m}$. In Figure 10 , the A-scan signals show that the signal amplitude is proportional to the size of the scattering part of the cable. The position $y_{\text {meas }}=0 \mathrm{~m}$ corresponds to the largest diameter $(74 \mathrm{~mm}), y_{\text {meas }}=0.4 \mathrm{~m}$ corresponds to the smallest diameter $(48 \mathrm{~mm})$ and the position $y_{\text {meas }}=0.25 \mathrm{~m}$ is the intermediate region between the junction and the cable where the diameter is between $48 \mathrm{~mm}$ and $74 \mathrm{~mm}$.

Finally, for imaging purpose a Kirchhoff migration technique 37-42] has been applied to the data of $E_{\text {tot }}-\left\langle E_{\text {tot }}\right\rangle$ and filtered $E_{\text {tot }}$ and the results are shown in Figure 11. The buried cable and its junction are clearly identified either for dry sand or wet one and either for parallel polarization or for perpendicular one.

As a conclusion the simulation analysis of the GPR scene composed of a cable buried in a sandbox respecting different polarizations and for two commonly existing environments: dry sand and wet sand with $20 \%$ humidity is proposed. The actual fractal V-folded bowtie antennas (VFBA) are used in a bistatic configuration for transmitting and receiving the electromagnetic field in the frequency band $[0.5 \mathrm{GHz}-3 \mathrm{GHz}]$. Up to here the electromagnetic (EM) modeling taking into account the coupling between the antennas and the sandbox was the main interest. The EM modeling has proven that the cable junction is detectable using a GPR technique in the frequency band [0.5 GHz $-3 \mathrm{GHz}]$. The results presented for $E_{\text {tot }}$ are not trivial for the localization of the junction, however, using $E_{\mathrm{tot}}-\left\langle E_{\mathrm{tot}}\right\rangle$ and filtered $E_{\mathrm{tot}}$ the junction can be localized. The filtering technique is simply implemented for efficient clutter reduction as presented. In addition, the Kirchhoff migration technique has shown good results for the localization of the junction based on a unique B-scan along the buried cable. In the next part, the results with experimental on-site measurements will be carried out in a real (even if controlled) environment.

\section{On-site measurement results}

We have carried out a measurement campaign inside a controlled area in "Electricité De France - R\&D" company with the laboratory of electrical material at Moret sur Loing site (EDF lab Les Renardières). The photography 

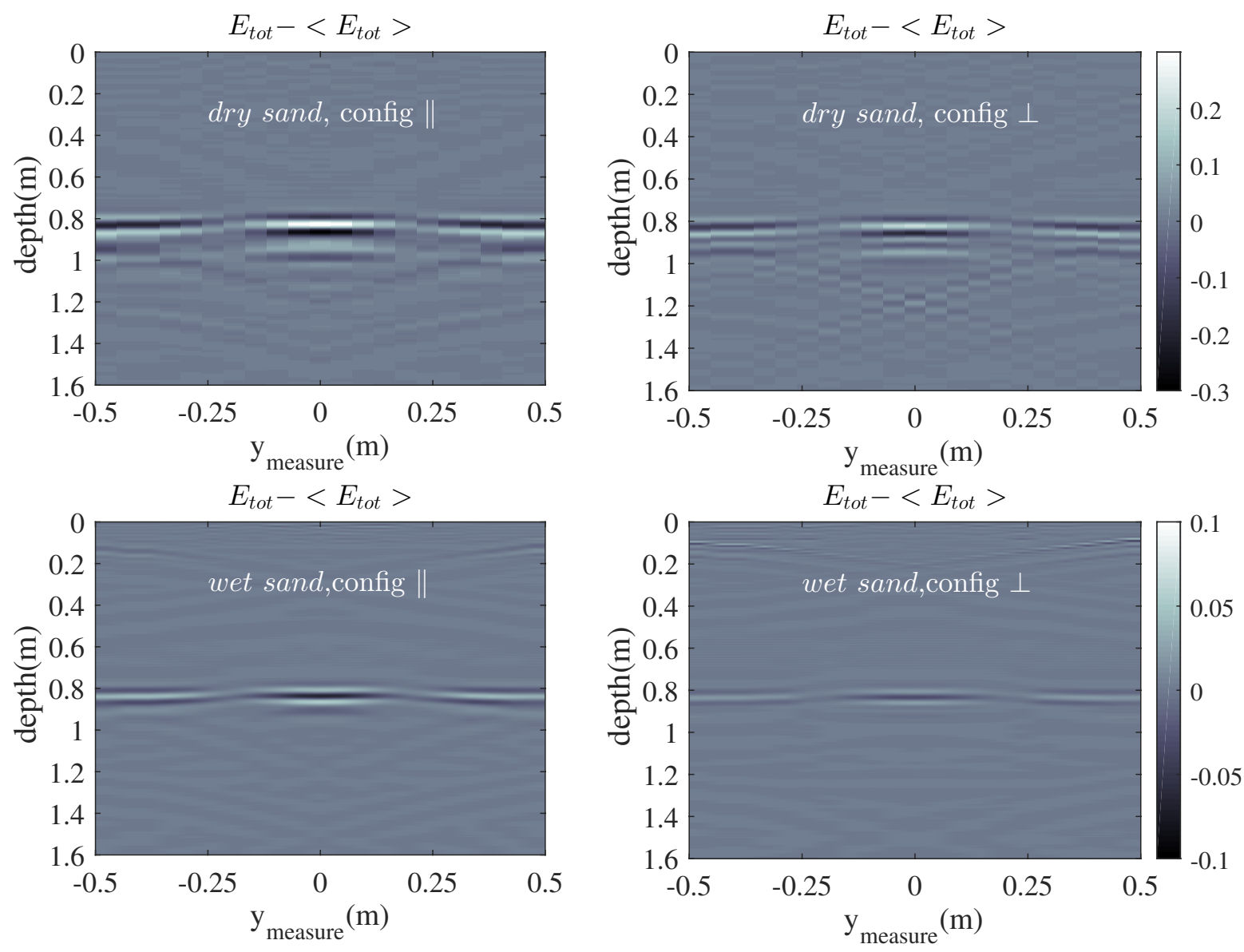

(a) $E_{\text {tot }}-\left\langle E_{\text {tot }}\right\rangle$
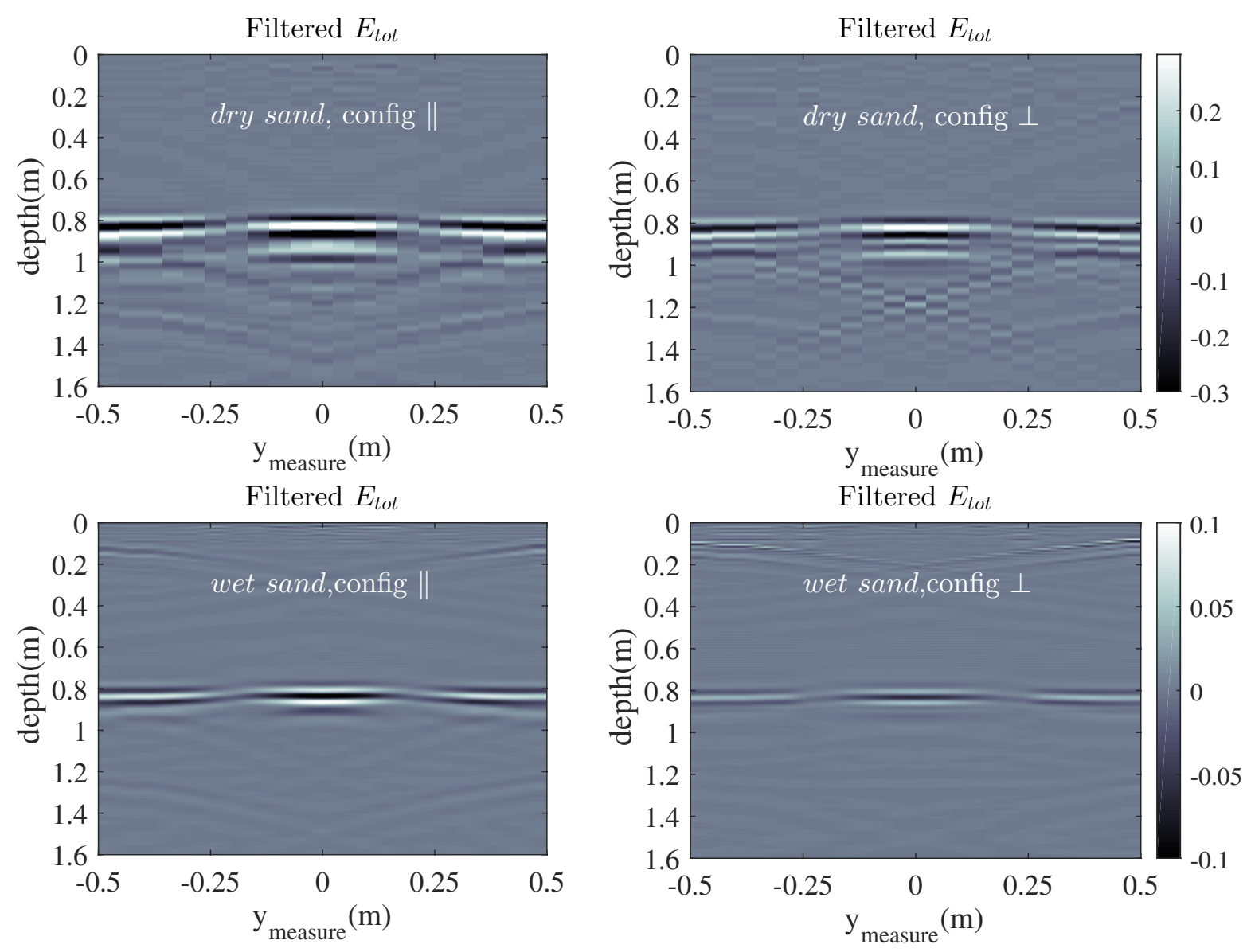

(b) Filtered $E_{\text {tot }}$ 

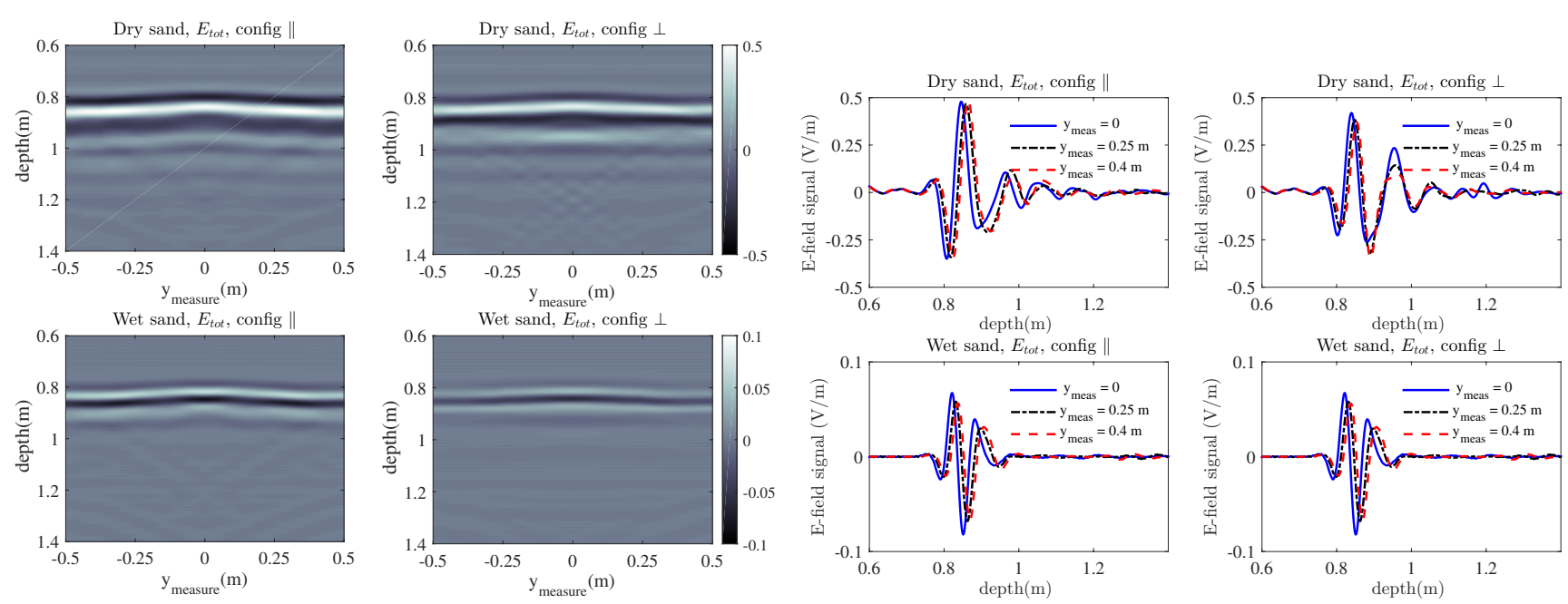

(a)

(b)

Figure 10: (a) Bscan radargram of the total field corresponding to the four studied situations. (b) Comparison of A-scan at $y_{\text {meas }}=$ $0,0.25,0.4 \mathrm{~m}$.

of this site is depicted in Figure 12 and shows the measurement area and cables before being buried. The cables are placed at around $1 \mathrm{~m}$ depth from the soil surface and the covers seen in the photography are removed before burying the entire scene. We scanned over $4 \mathrm{~m}$ along a cable as shown in Figure 12 , where the junction is localized with the wooden stick (preserved after burying the cables) seen at the right of the photography.

As seen in Figure 12, the buried cables are not identical to the simulated one; they are gathered by pair and have a larger diameter (total diameter of about $90 \mathrm{~mm}$ ) and the junction we are investigating is also larger since it contains the junctions of two cables. The diameter of the buried junction is around $200 \mathrm{~mm}$. The FrequencyStepped Continuous Wave (FSCW) GPR technique has been used to measure the scattered field using the cavity backed V-folded fractal bowtie antennas and the vector network analyzer Agilent ENA E5071 in the frequency band $[0.1 \mathrm{GHz}-3.1 \mathrm{GHz}]$ over 1201 frequency points (Figure 13 ). Then the frequency domain data are transformed to extract the B-scan radargram according to the pulse previously depicted in Figure 6 For each measurement position along the cable the controlling computer acquires the transmission parameter $S_{21}$. The measurement data are collected along the scanning line presented in Figure 12 and the network analyzer has been calibrated before starting the scan. The antennas are moved manually step by step along $4 \mathrm{~m}$ with a displacement step of $5 \mathrm{~cm}$. Unlike the simulation study the surface of the soil is not flat and the soil is not homogeneous.

In order to evaluate the wave velocity in the ground, we have collected a sample of the soil and we measured the permittivity in the frequency band of interest using a coaxial probe in the laboratory. The results are shown in Figure 14. The measured real part of the permittivity of the soil is about 2.69 and the imaginary part is about 0.07. Using the same permittivity measurement technique, we have measured the permittivity of the air as a reference. Indeed, the average of the measured real part of the air permittivity is about 1.04 and the imaginary part is about -0.006 . These measurement results are used in the B-scan radargram representation to achieve the time to distance transformation for the cable and junction localization. The measurement has been conducted in July with a dry soil.

The B-scan is obtained for the parallel and perpendicular polarizations. The radargrams are presented in Figure 15. In comparison with the simulation results, the clutter in the radargrams for $E_{\text {tot }}$ is higher mainly 

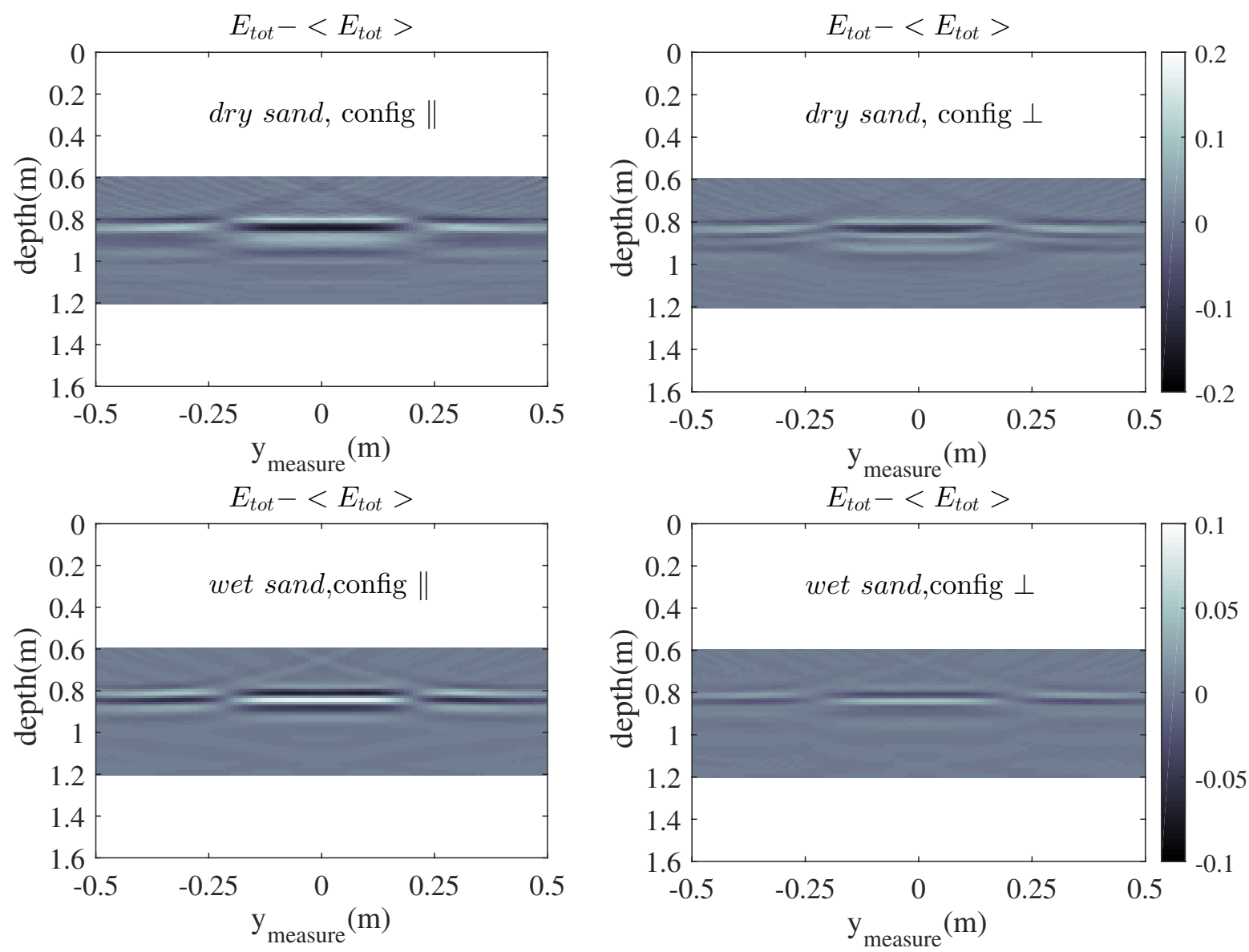

(a) $E_{\text {tot }}-\left\langle E_{\text {tot }}\right\rangle$
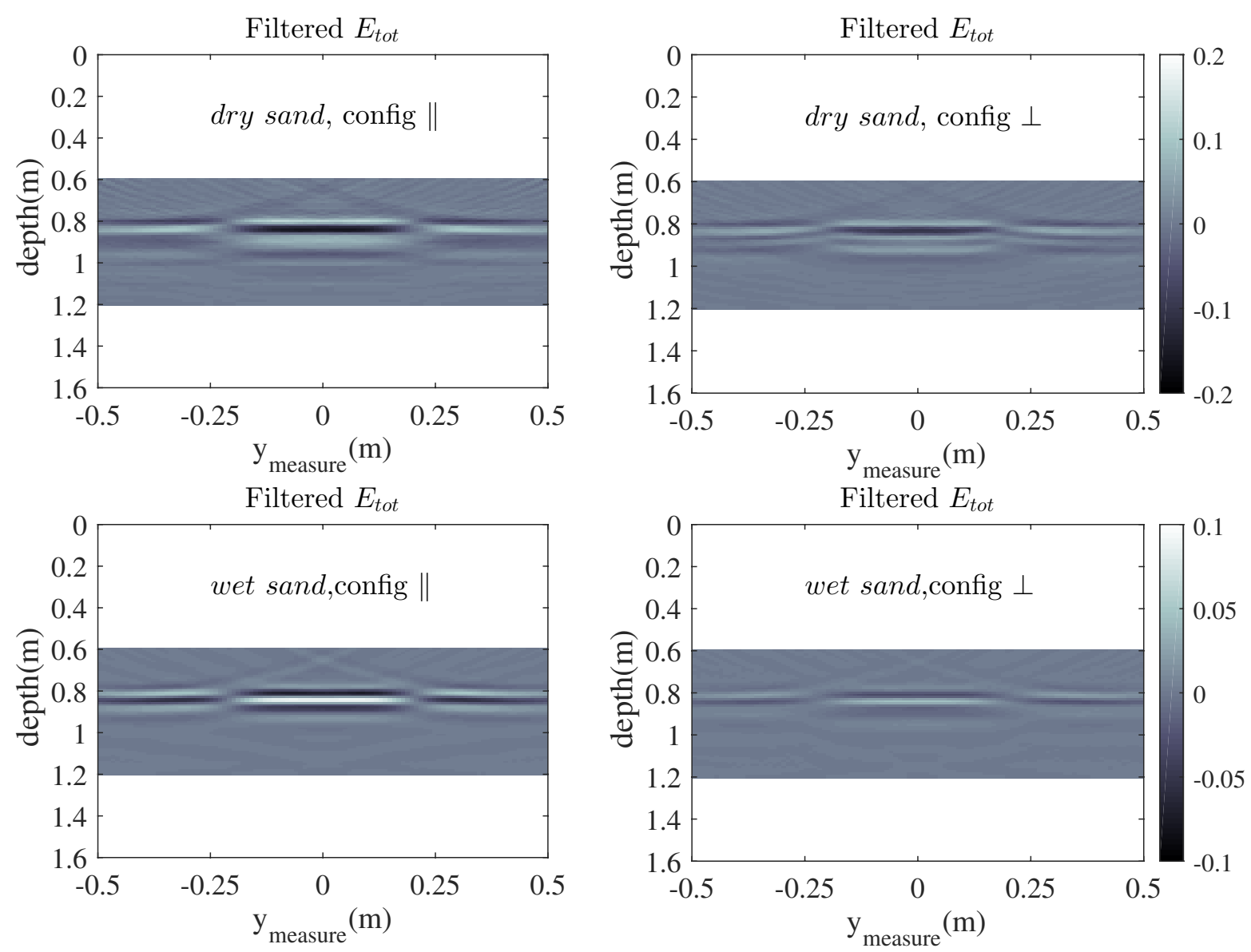

(b) Filtered $E_{\text {tot }}$

Figure 11: Kirchhoff migration resulting from 4 situations associated with (a) $E_{\text {tot }}-\left\langle E_{\text {tot }}\right\rangle$ (b) Filtered $E_{\text {tot }}$. 


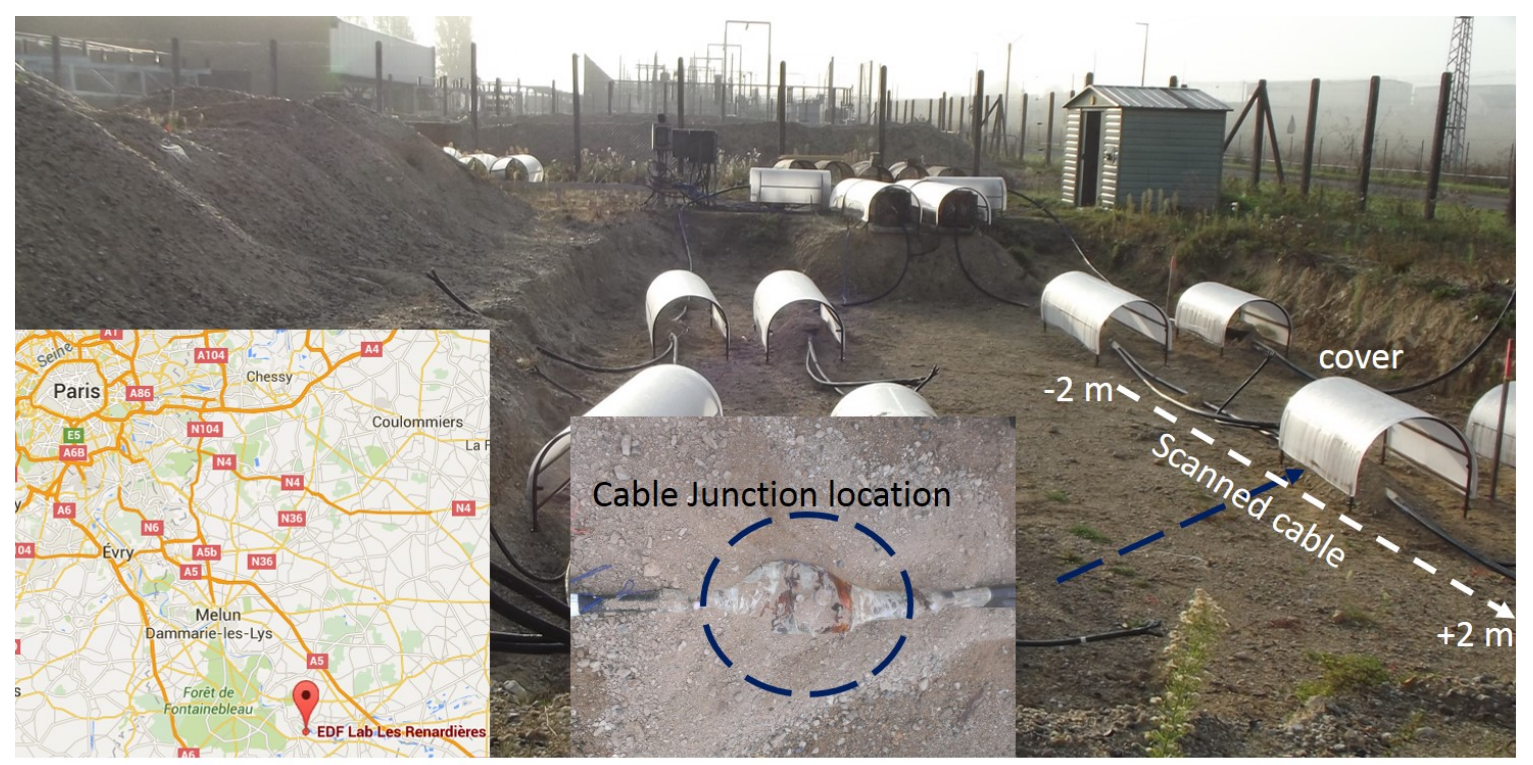

Measurement location

Figure 12: The measurement area at EDF-lab.
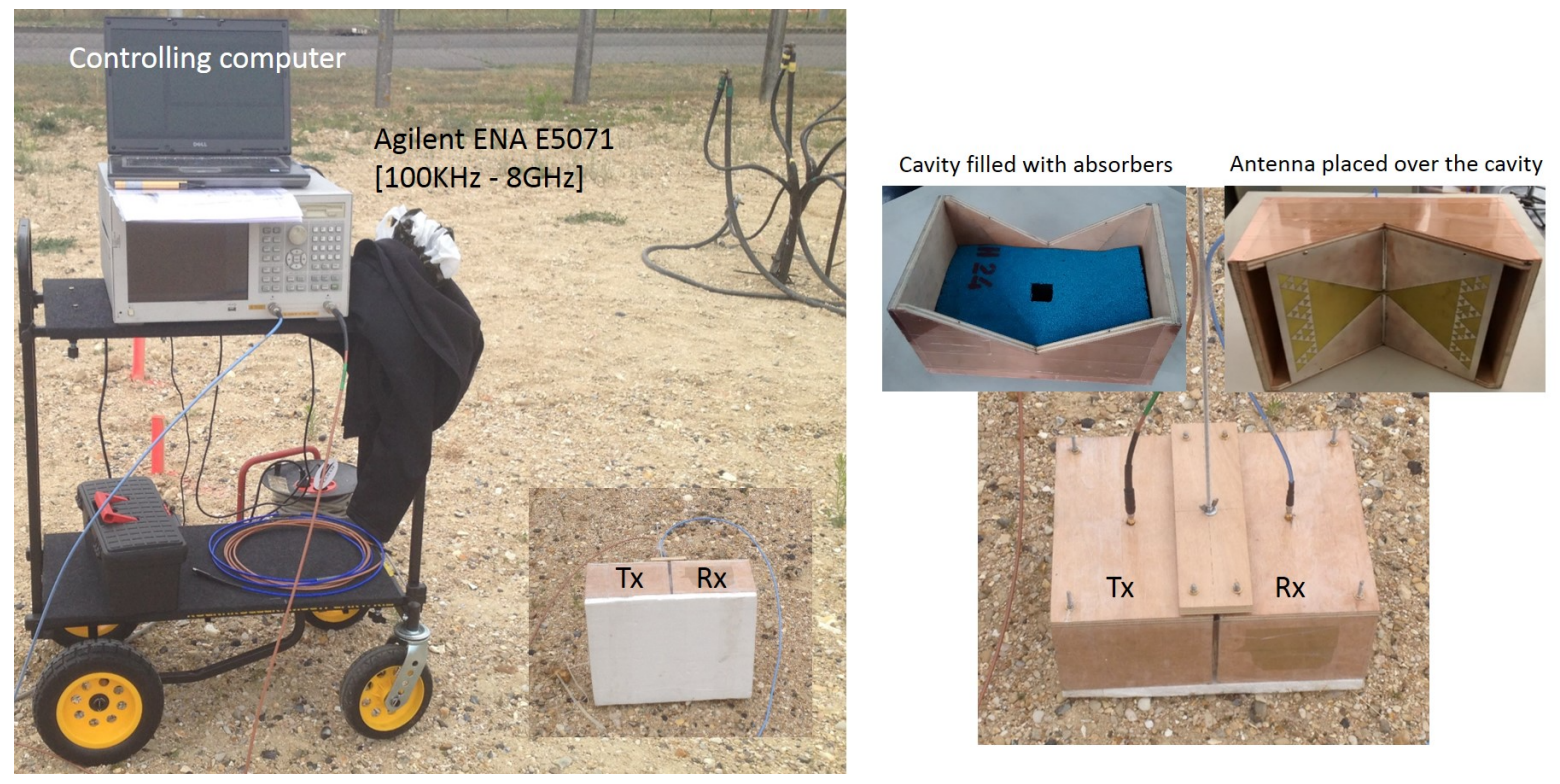

Figure 13: (left) Vector Network Analyzer and controlling computer, (right) transmitting and receiving antennas cavity backed V-folded bowtie antennas. 

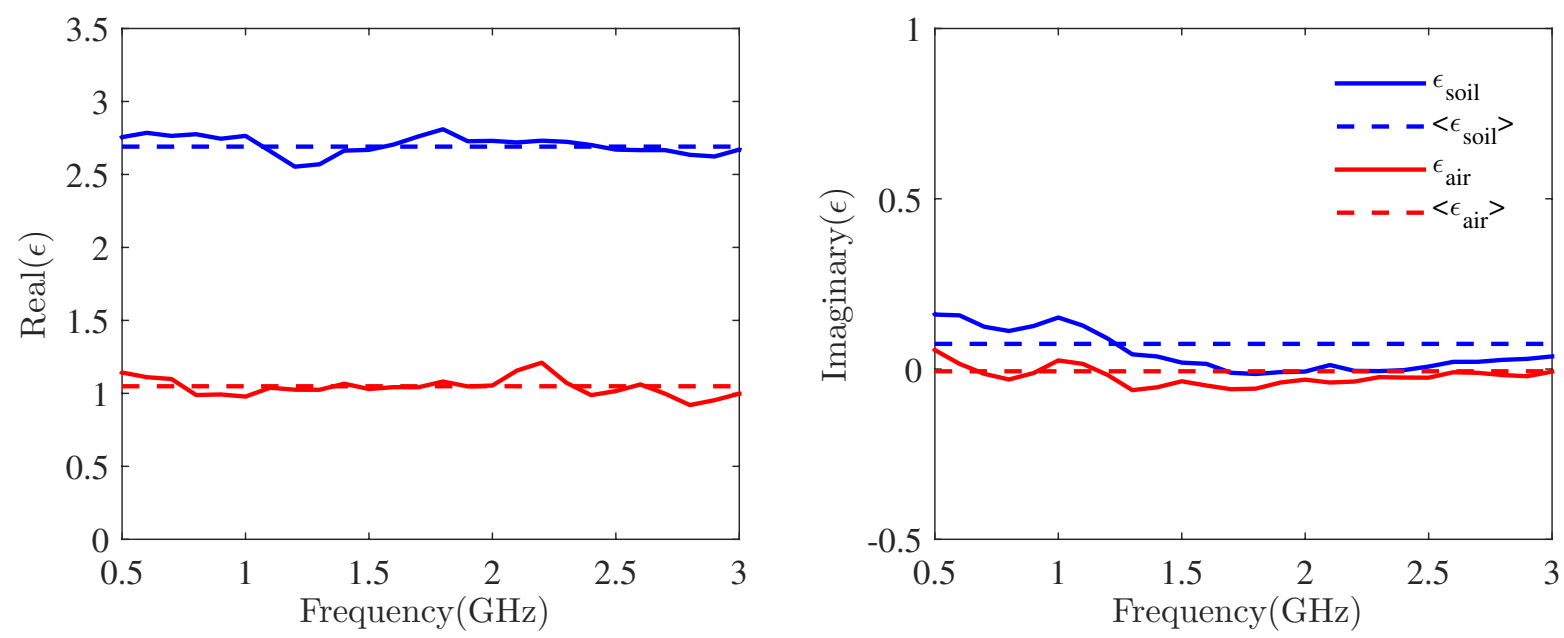

Figure 14: Measured epsilon of a sand sample collected at the measurement site, (left) real part, (right) imaginary part.

caused by the soil heterogeneities. In addition, the antennas response is differently coupled with the non-flat soil. Using the cavity-backed antennas we prevent the external environment coupling, however we distort the shortness of the antenna transient response. Based on the radargram of $E_{\text {tot }}$, the cable silhouette is clearly visible between $1 \mathrm{~m}$ and $1.4 \mathrm{~m}$ depth and the junction corresponds to the brightest zone at $1 \mathrm{~m}$ depth at the measurement position $0.5 \mathrm{~m}$. This is applicable for both parallel and perpendicular polarizations.

We have focused our effort on the clutter reduction in the depth range $0.8 \mathrm{~m}<$ depth $<1.6 \mathrm{~m}$. After time gating the measured signal, we have used two techniques for clutter reduction. First the averaging technique to cancel a part of the clutter as presented in Figure $15 E_{\mathrm{tot}}-\left\langle E_{\mathrm{tot}}\right\rangle$ applied for $0.8 \mathrm{~m}<$ depth $<1.6 \mathrm{~m}$ considerably reduced the clutter and the cable is easily identified. In a second time, we have used the digital filtering technique proposed in [36] with the same conclusion. Both techniques help at enhancing the detectability of the buried cable and consequently the junction is localized at $1 \mathrm{~m}$ depth at the measurement position $y_{\text {meas }}=0.5 \mathrm{~m}$ as expected. The parallel polarization is more efficient that the perpendicular one which confirms the simulation results.

In Figure 16, we present the imaging results of the Kirchhoff migration technique resulting from the measurement data. As it is seen, in the parallel configuration the cable and its junction are easily identified using $E_{\text {tot }}-\left\langle E_{\text {tot }}\right\rangle$ and filtered $E_{\text {tot }}$. However, in the case of cluttered data, the cable is hardly detectable after the Kirchhoff migration for the perpendicular configuration.

\section{Conclusion}

In this paper we have shown that the high frequency GPR technique is an efficient non-destructive technique able to accurately detect the location of the buried power cables. Using a unique B-scan measurement along the cable, the junction is clearly detected against the cluttered environment. As a priori information we know the position of the cable. We have considered a complex GPR scene for our electromagnetic modeling study comprising the actual antennas. Comparison between experimental data (anechoic chamber) and synthetic data either computed using CST-MWS or using a laboratory-made software based on Discontinuous Galerkin Time-Domain method are presented in [43, 44] and has not been reproduced here.

First, we have optimized the fractal V-folded bowtie antenna for the frequency band $[0.5 \mathrm{GHz}-3 \mathrm{GHz}]$. Then, we have presented the scattered field of a buried cable using a rigorous model of the cable provided by Electricity De 

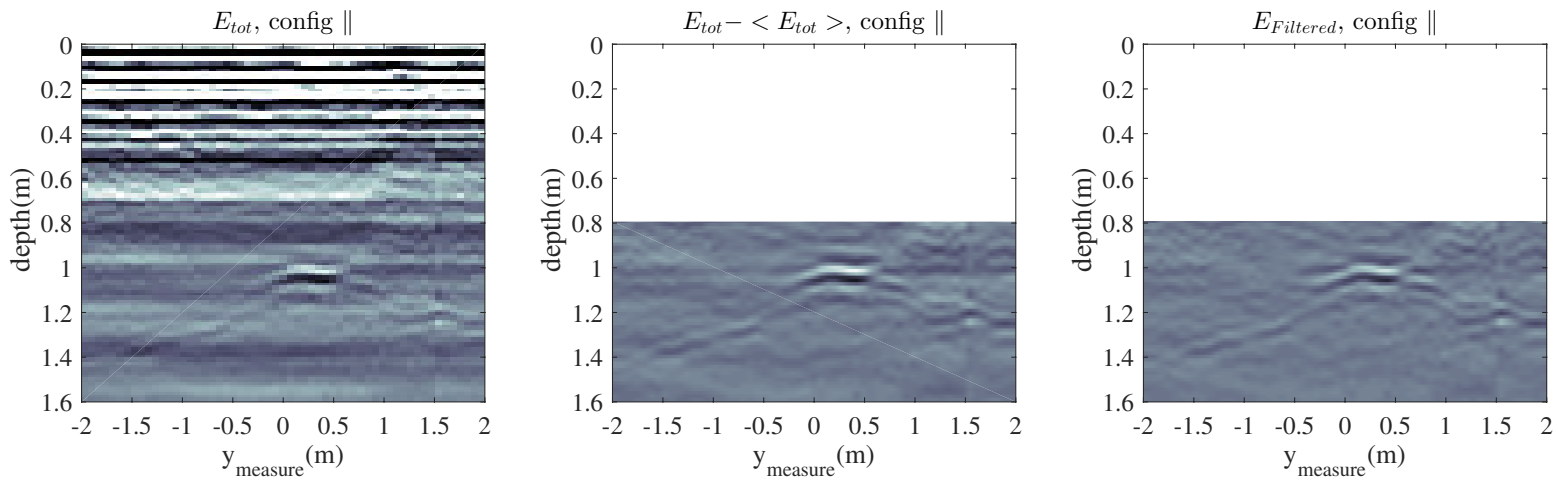

(a) $E_{\text {tot }}-\left\langle E_{\text {tot }}\right\rangle$
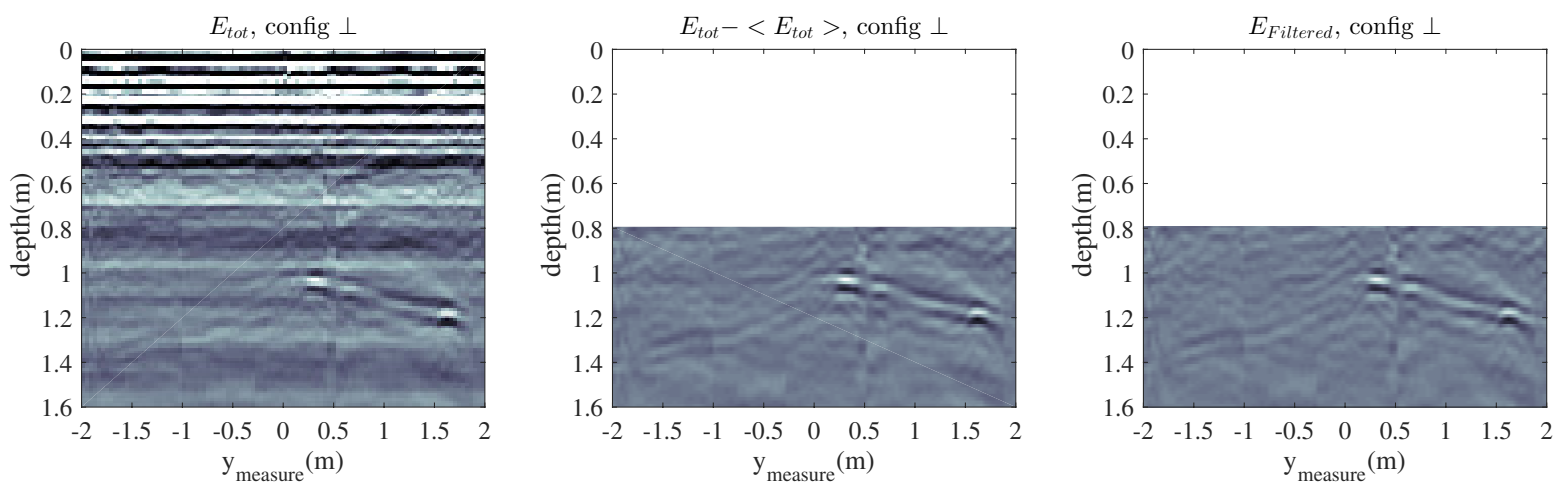

(b) Filtered $E_{\text {tot }}$

Figure 15: B-scan radargrams of $E_{\mathrm{tot}}, E_{\mathrm{tot}}-\left\langle E_{\mathrm{tot}}\right\rangle$ and filtered $E_{\mathrm{tot}}$ corresponding to parallel polarization in (a) and perpendicular polarization in (b). 

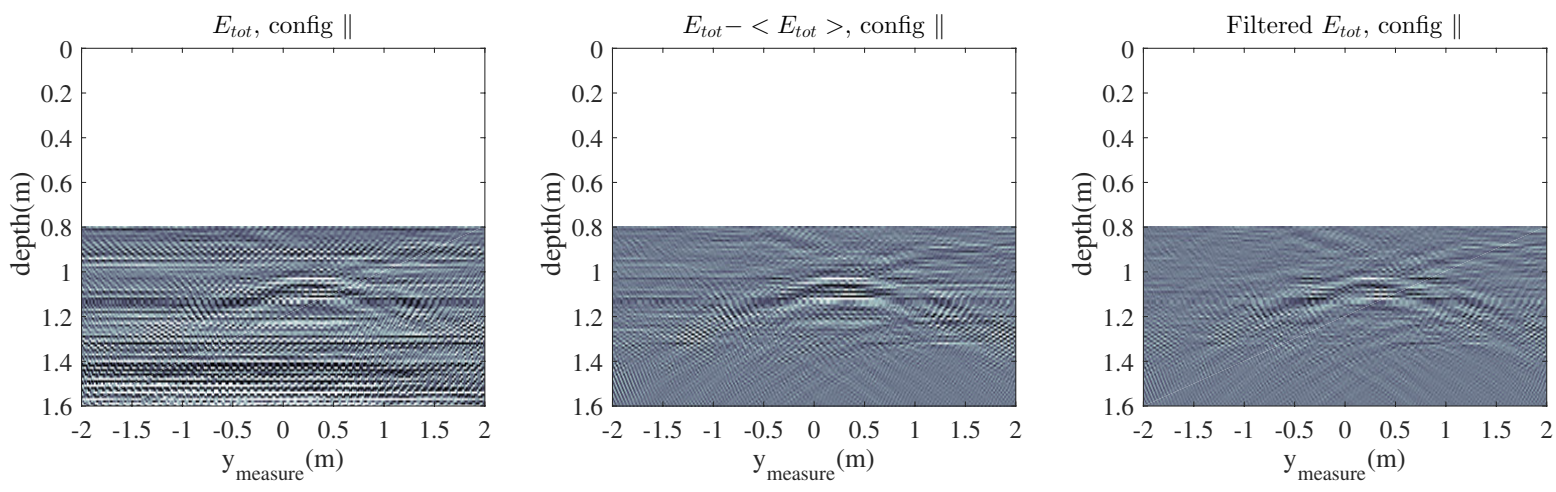

(a) $E_{\text {tot }}-\left\langle E_{\text {tot }}\right\rangle$
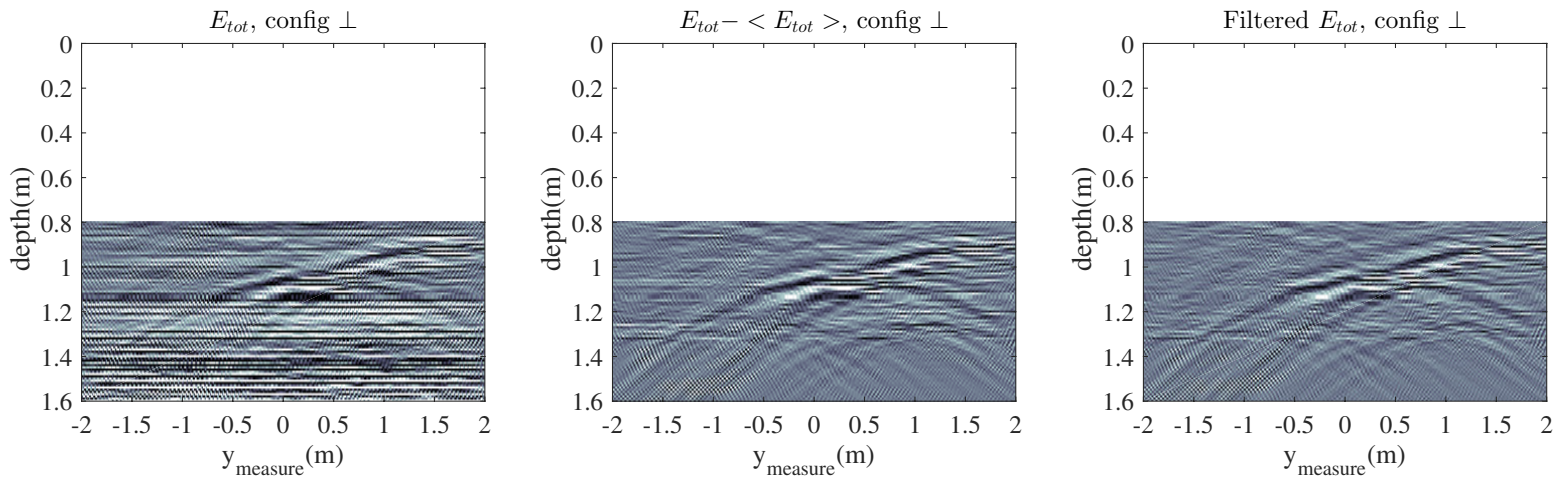

(b) Filtered $E_{\text {tot }}$

Figure 16: Kirchhoff migration results of $E_{\mathrm{tot}}, E_{\mathrm{tot}}-\left\langle E_{\mathrm{tot}}\right\rangle$ and filtered $E_{\mathrm{tot}}$ for parallel (a) and perpendicular (b) configuration.

France R\&D. Two homogeneous burying environments have been used (wet and dry sands) which is a simplification of the real soil. However, the measurement campaign carried out in the actual environment have proved that high frequency GPR technique is an efficient tool for the buried cables detection. For the clutter reduction we have exploited two different methods that bring the same enhancement to the measured B-scan. Based on experimental data collected at the measurement site, the cable is localized if its depth is greater than $0.5 \mathrm{~m}$. Indeed, the clutter due to the antenna response ringing and the soil inhomogeneity, engender parasitic oscillation that are hardly filtered. For shallowly buried cable, this technique is not efficient. Also, the polarization of the transmitting and receiving antennas has been investigated. Parallel polarization is recommended for use since the scattered field is higher.

From the antenna point of view, the VFBA is bent so the distance between the excitation part of the antenna (central part) and the soil is about $7 \mathrm{~cm}$, which helps to keep the antenna matching stable even in front of a wet environment. The risk of placing the antenna in front of high conductive medium is that the reflected signal is strong enough to mismatch the antenna excitation. Consequently, the energy accepted by the antenna is reduced.

\section{Acknowledgment}

This research was carried out within the framework of EU funded COST Action TU1208 Civil Engineering Applications of Ground Penetrating Radar. The authors wish to acknowledge the help of Dr. Céline Miry and Dr. Emmanuel Amador from EDF R\&D for providing us the opportunity to do the measurement at the EDF site. 


\section{References}

[1] D. J. Daniels, Ground Penetrating Radar, John Wiley \& Sons, Inc., 2005. doi :10.1002/0471654507.eme152

[2] A. Benedetto, L. Pajewski (Eds.), Civil Engineering Applications of Ground Penetrating Radar, Springer Transactions in Civil and Environmental Engineering, Springer International Publishing, 2015. doi:10.1007/ $978-3-319-04813-0$

[3] J. Stryk, R. Matula, K. Pospisil, Possibilities of ground penetrating radar usage within acceptance tests of rigid pavements, J. Appl. Geophys. 97 (Supplement C) (2013) 11 - 26, ground Penetrating Radar. doi: $10.1016 / \mathrm{j} \cdot \mathrm{jappgeo} .2013 .06 .013$

[4] S. Laurens, J. P. Balayssac, J. Rhazi, G. Klysz, G. Arliguie, Non-destructive evaluation of concrete moisture by GPR: Experimental study and direct modeling, Mater. Struct. 38 (9) (2005) 827-832. doi:10.1007/ BF02481655.

[5] A. Loizos, C. Plati, Accuracy of pavement thicknesses estimation using different ground penetrating radar analysis approaches, NDT\&E Int 40 (2) (2007) 147 - 157. doi:10.1016/j.ndteint.2006.09.001.

[6] J. A. Huisman, S. S. Hubbard, J. D. Redman, A. P. Annan, Measuring soil water content with ground penetrating radar, Vadose Zone J. 2 (4) (2003) 476-491. doi:10.2113/2.4.476

[7] A. Benedetto, Water content evaluation in unsaturated soil using GPR signal analysis in the frequency domain, J. Appl. Geophys. 71 (1) (2010) 26 - 35. doi:10.1016/j.jappgeo.2010.03.001.

[8] F. Tosti, E. Slob, Determination, by using GPR, of the volumetric water content in structures, substructures, foundations and soil, in: A. Benedetto, L. Pajewski (Eds.), Civil Engineering Applications of Ground Penetrating Radar, Springer International Publishing, Cham, 2015, pp. 163-194. doi:10.1007/978-3-319-04813-0_ 7 .

[9] C. Patriarca, F. Tosti, C. Velds, A. Benedetto, S. Lambot, E. Slob, Frequency dependent electric properties of homogeneous multi-phase lossy media in the ground-penetrating radar frequency range, J. Appl. Geophys. 97 (Supplement C) (2013) 81 - 88. doi:10.1016/j.jappgeo.2013.05.003.

[10] S. Lambot, L. Weihermüller, J. A. Huisman, H. Vereecken, M. Vanclooster, E. C. Slob, Analysis of air-launched ground-penetrating radar techniques to measure the soil surface water content, Water Resour. Res. 42 (11) (2006) W11403. doi:10.1029/2006WR005097.

[11] M. Solla, H. Lorenzo, F. Rial, A. Novo, Ground-penetrating radar for the structural evaluation of masonry bridges: Results and interpretational tools, Constr. Build. Mater. 29 (Supplement C) (2012) 458 - 465 . doi: $10.1016 / \mathrm{j}$. conbuildmat.2011.10.001

[12] A. Benedetto, G. Manacorda, A. Simi, F. Tosti, Novel perspectives in bridges inspection using GPR, Nondestruct Test Eva 27 (3) (2012) 239-251. doi:10.1080/10589759.2012.694883.

[13] S. Seren, A. Eder-Hinterleitner, W. Neubauer, K. Löcker, P. Melichar, Extended comparison of different GPR systems and antenna configurations at the roman site of carnuntum, Near Surf. Geophys. 5 (6) (2007) 389-394. doi:10.3997/1873-0604.2007021 
[14] C. W. Chang, C. H. Lin, H. S. Lien, Measurement radius of reinforcing steel bar in concrete using digital image gpr, Constr. Build. Mater. 23 (2) (2009) 1057 - 1063. doi:10.1016/j.conbuildmat.2008.05.018.

[15] F. Soldovieri, R. Solimene, L. L. Monte, M. Bavusi, A. Loperte, Sparse reconstruction from gpr data with applications to rebar detection, IEEE Trans. Instrum. Meas. 60 (3) (2011) 1070-1079. doi:10.1109/TIM. 2010.2078310 .

[16] S. Shihab, W. Al-Nuaimy, Radius estimation for cylindrical objects detected by ground penetrating radar, Subsurface Sensing Technologies and Applications 6 (2) (2005) 151-166. doi:10.1007/s11220-005-0004-1.

[17] L. Zanzi, D. Arosio, Sensitivity and accuracy in rebar diameter measurements from dual-polarized GPR data, Constr. Build. Mater. 48 (Supplement C) (2013) 1293 - 1301. doi:10.1016/j.conbuildmat.2013.05.009.

[18] X.-Q. He, Z.-Q. Zhu, Q.-Y. Liu, G.-Y. Lu, Review of GPR rebar detection, in: PIERS Proceedings, 2009, pp. 804-813.

[19] S. Lambot, F. André, Full-wave modeling of near-field radar data for planar layered media reconstruction, IEEE Trans. Geosci. Remote Sensing 52 (5) (2014) 2295-2303. doi:10.1109/TGRS. 2013.2259243.

[20] S. Lambot, E. C. Slob, I. van den Bosch, B. Stockbroeckx, M. Vanclooster, Modeling of ground-penetrating radar for accurate characterization of subsurface electric properties, IEEE Trans. Geosci. Remote Sensing 42 (11) (2004) 2555-2568. doi:10.1109/TGRS. 2004.834800

[21] G. Klysz, X. Ferrieres, J. Balayssac, S. Laurens, Simulation of direct wave propagation by numerical fdtd for a gpr coupled antenna, NDT\&E Int 39 (4) (2006) 338 -347. doi:10.1016/j.ndteint.2005.10.001.

[22] R. Streich, J. v. d. Kruk, Accurate imaging of multicomponent gpr data based on exact radiation patterns, IEEE Trans. Geosci. Remote Sensing 45 (1) (2007) 93-103. doi:10.1109/TGRS.2006.883459

[23] A. P. Tran, F. André, S. Lambot, Validation of near-field ground-penetrating radar modeling using fullwave inversion for soil moisture estimation, IEEE Trans. Geosci. Remote Sensing 52 (9) (2014) 5483-5497. doi:10.1109/TGRS.2013.2289952

[24] C. Warren, A. Giannopoulos, Experimental and modeled performance of a ground penetrating radar antenna in lossy dielectrics, IEEE J. Sel. Topics Appl. Earth Observ. Remote Sens. 9 (1) (2016) 29-36, eP/I501363. doi:10.1109/JSTARS.2015.2430933.

[25] N. Diamanti, A. P. Annan, Characterizing the energy distribution around GPR antennas, J. Appl. Geophys. 99 (Supplement C) (2013) 83 - 90. doi:10.1016/j.jappgeo.2013.08.001.

[26] C. Warren, A. Giannopoulos, I. Giannakis, gprmax: Open source software to simulate electromagnetic wave propagation for ground penetrating radar, Comput. Phys. Commun. 209 (2016) 163 - 170. doi:10.1016/j. cpc.2016.08.020.

[27] X. Begaud, F. Bucaille, J.-Y. Dauvignac, C. Delaveaud, N. Fortino, S. Hetuin, G. Kossiavas, C. Roblin, A. Sibille, Ultra wide band antennas, John Wiley \& Sons, 2011. 
[28] W. Wiesbeck, G. Adamiuk, C. Sturm, Basic properties and design principles of UWB antennas, Proc. IEEE 97 (2) (2009) 372-385. doi:10.1109/JPROC.2008.2008838.

[29] A. Yarovoy, A. Schukin, L. Ligthart, Development of dielectric filled tem-horn, AP2000.

[30] R. Carrel, The characteristic impedance of two infinite cones of arbitrary cross section, IRE Trans. Anntenas Propag. 6 (2) (1958) 197-201. doi:10.1109/TAP.1958.1144578.

[31] A. A. Lestari, E. Bharata, A. B. Suksmono, A. Kurniawan, A. G. Yarovoy, L. P. Ligthart, A modified bowtie antenna for improved pulse radiation, IEEE Trans. Antennas Propagat. 58 (7) (2010) 2184-2192. doi: 10.1109/TAP.2010.2048853

[32] S. W. Qu, J. L. Li, Q. Xue, C. H. Chan, S. Li, Wideband and unidirectional cavity-backed folded triangular bowtie antenna, IEEE Trans. Antennas Propagat. 57 (4) (2009) 1259-1263. doi:10.1109/TAP.2009.2015845

[33] S. W. Qu, J. L. Li, Q. Xue, C. H. Chan, Wideband cavity-backed bowtie antenna with pattern improvement, IEEE Trans. Antennas Propagat. 56 (12) (2008) 3850-3854. doi:10.1109/TAP.2008.2007395.

[34] F. Sagnard, Design of a compact ultra-wide band bow-tie slot antenna system for the evaluation of structural changes in civil engineering works, Progress in Electromagnetic Research B 58 (2014) pp. 181-191. doi: 10.2528/PIERB14013004.

[35] R. T. Lee, G. S. Smith, A design study for the basic tem horn antenna, IEEE Antennas Propagat. Mag. 46 (1) (2004) 86-92. doi:10.1109/MAP.2004.1296150

[36] D. Potin, E. Duflos, P. Vanheeghe, Landmines ground-penetrating radar signal enhancement by digital filtering, IEEE Trans. Geosci. Remote Sensing 44 (9) (2006) 2393-2406. doi:10.1109/TGRS.2006.875356.

[37] J. G. Hagedoorn, A process of seismic reflection interpretation, Geophys. Prospect. 2 (2) (1954) 85-127. doi:10.1111/j.1365-2478.1954.tb01281.x

[38] J. Gazdag, P. Sguazzero, Migration of seismic data, Proc. IEEE 72 (10) (1984) 1302-1315. doi:10.1109/ PROC.1984.13019.

[39] F. Soldovieri, O. Lopera, S. Lambot, Combination of advanced inversion techniques for an accurate target localization via GPR for demining applications, IEEE Trans. Geosci. Remote Sensing 49 (1) (2011) 451-461. doi:10.1109/TGRS.2010.2051675

[40] J. M. Lopez-Sanchez, J. Fortuny-Guasch, 3-D radar imaging using range migration techniques, IEEE Trans. Antennas Propagat. 48 (5) (2000) 728-737. doi:10.1109/8.855491

[41] W. A. Schneider, Integral formulation for migration in two and three dimensions, Geophysics 43 (1) (1978) 49-76. doi:10.1190/1.1440828.

[42] F. Soldovieri, R. Solimene, Radar Technology, InTech, 2010, Ch. Ground Penetrating Radar Subsurface Imaging of Buried Objects. doi:10.5772/7176 
335 [43] X. Liu, M. Serhir, A. Kameni, M. Lambert, L. Pichon, 3-D discontinuous galerkin time-domain antenna 336 modelling and overall ground-penetration radar scenario, in: 10th International Symposium on Electric and 337 Magnetic Fields (EMF 2016), Lyon, France, pp. PC-1.

[44] X. Liu, M. Serhir, A. Kameni, M. Lambert, L. Pichon, GPR imaging via multi-frequency linear sampling method, in: 10th International Symposium on Electric and Magnetic Fields (EMF 2016), Lyon, France, pp. OA3-2. 